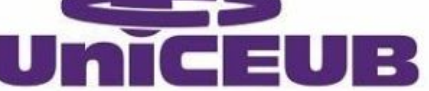 \\ EDUCAÇÃO SUPERIOR \\ CENTRO UNIVERSITÁRIO DE BRASÍLIA - UnICEUB \\ PROGRAMA DE INICIAÇÃO CIENTÍFICA
}

\author{
LEONARDO RUBINGER BETTI \\ CAROLINA CARDOSO DE OLIVEIRA
}

CARACTERIZAÇÃO DA DINÂMICA COMPORTAMENTAL E REPRODUTIVA DAS POPULAÇÕES DE CAPIVARAS

BRASÍLIA 


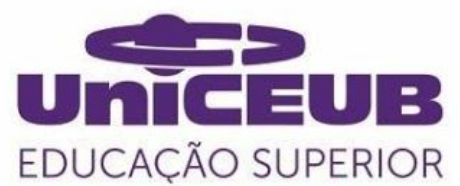

EDUCAC̨ÃO SUPERIOR

LEONARDO RUBINGER BETTI

CAROLINA CARDOSO DE OLIVEIRA

\section{CARACTERIZAÇÃO DA DINÂMICA COMPORTAMENTAL E REPRODUTIVA DAS POPULAÇÕES DE CAPIVARAS}

Relatório final de pesquisa de Iniciação Científica apresentado à Assessoria de Pós-Graduação e Pesquisa.

Orientação: Prof. Dr. Andrei Antonioni Guedes Fidelis

\section{BRASÍLIA}




\section{RESUMO}

A capivara (Hydrochoerus hydrochaeris) é um animal nativo da América do Sul, considerado o maior roedor vivo do mundo, que possui grande capacidade adaptativa e populações distribuídas por grande parte do território brasileiro habitando diversos biomas mesmo que antropizados, desde que associados a corpos d'água. O projeto de caracterização da dinâmica comportamental e reprodutiva das populações de capivaras teve como objetivo aplicar técnicas de condicionamento animal aos grupos de capivaras livres que habitam os lagos artificiais do Jardim Zoológico de Brasília, tendo como foco principal as fêmeas, de modo que fosse possível o manejo destes indivíduos viabilizando a administração de doses da vacina contraceptiva e conseguinte acompanhamento médico veterinário por meio de diferentes exames e, em seu decorrer, avaliar a estrutura e interação social das capivaras considerando as possíveis alterações de dominância e de padrões comportamentais reprodutivos como consequência de uma esterilização eficaz e/ou manejo de indivíduos. As observações dos grupos de capivaras foram realizadas cinco vezes por semana nos turnos matutino e vespertino durante o período de setembro à março dos anos de 2019 e 2020 . Os comportamentos mais observados estão relacionados diretamente com a tentativa de condicionamento por reforço positivo destes animais e suas consequentes respostas a ele. Os achados sugerem que o condicionamento sofre influência direta de variáveis tais como: período de tempo seco ou chuvoso, comportamento alimentar natural e seletividade em relação à alimentos oferecidos, diferentes taxas de atividade durante as horas do dia, frequência de contato humano com animais alvo e até personalidade individual de cada animal. Além disto, foi relatado que o grupo estudado possui menor atividade diurna do que a literatura descreve em relação a animais de vida livre, possivelmente devido à influência antrópica local.

Palavras-chave: Capivaras. Comportamento. Condicionamento. Esterilização. Zoológico de Brasília. 
SUMÁRIO

INTRODUÇÃO

FUNDAMENTAÇÃO TEÓRICA

$\begin{array}{ll}\text { METODOLOGIA } & 8\end{array}$

RESULTADOS E DISCUSSÃO 9

CONCLUSÃO

REFERÊNCIAS BIBLIOGRÁFICAS 


\section{INTRODUÇÃO}

A capivara (Hydrochoerus hydrochaeris) é membro da Família família Caviidae, ordem Rodentia, é um mamífero semi-aquático e o maior roedor herbívoro. São encontradas amplamente por toda América do sul e grandes populações ocorrem em todas as regiões do Brasil (FERRAZ e VERDADE, 2001). Seu habitat natural são locais preferencialmente quentes, com cursos d'água e campos para pastoreio (RODRIGUES, 2013). Naturalmente são animais diurnos, concentrando suas atividades nos períodos vespertino e crepuscular, suas atividades resumem-se em forragear nas primeiras horas da manhã, permanecer dentro d'água nas horas mais quentes da tarde e repousar em pequenos grupos ao anoitecer (FERRAZ, et al., 2001; FELIX, 2012). Porém, em centros urbanos, as capivaras podem se tornar ativas em terra somente a noite para evitar contato com os humanos, substituindo o forrageamento diurno por cecotrofia (OJASTI, 1973).

As capivaras apresentam hierarquia rígida formada por um macho dominante, alguns machos submissos, várias fêmeas e filhotes (RODRIGUES, 2013). Os machos interagem entre si com frequência sem agressão, e quando há, está relacionada com o número de machos presentes no bando (FERRAZ e VERDADE, 2001). Os grupos sociais variam de tamanho conforme o ambiente e extensão de corpos d'água, em áreas preservadas os grupos variam de três a 14 indivíduos, já em áreas antropizadas, os grupos podem conter mais de 40 adultos (MACDONALD, 1981).

O sistema de acasalamento da capivara é do tipo poligínico, ou seja, o macho pode acasalar com várias fêmeas do grupo e as fêmeas são submissas. A reprodução ocorre o ano todo mas tem um pico na época de chuva, em decorrência a alta disponibilidade de plantas forrageiras, a gestação dura aproximadamente 150 dias com taxa de fertilidade média de 4 filhotes por ano, podendo parir até 8 filhotes em uma ninhada, característica esta que lhe rendeu o título de herbívoro mais prolífico do mundo (FERRAZ e VERDADE, 2001; BARBOSA, 2007; FELIX, 2012). O projeto de caracterização da dinâmica comportamental e reprodutiva das populações de capivaras teve como objetivo aplicar técnicas de condicionamento animal por reforço positivo, aos grupos de capivaras livres que habitam os lagos das ilhas dos macacos, do Jardim Zoológico de Brasília. O foco principal do condicionamento foram as 
fêmeas jovens e solteiras (sem filhotes), para que fossem contidas e a administrada doses da vacina contraceptiva, avaliação das estruturas reprodutivas por ultrassom e coleta de material para análise dos efeitos da esterilização. 


\section{FUNDAMENTAÇÃO TEÓRICA}

Objetivos de manejo de população de animais podem ser em decorrência do declínio da população, que esteja ameaçada de extinção ou de seu aumento. $O$ crescimento de uma população está interligado com disponibilidade de água e alimento, e ausência de predadores. A capivara possui os dois requisitos para adaptação em meio urbano, além de possuir uma dieta adaptável, conseguindo se alimentar também de rejeito humano, praticamente não possui predadores naturais dispostos a segui-las para regiões tão afastadas de mata. Por isto, as capivaras vêm ocupando e se beneficiando de ambientes antropizados (FERRAZ et al., 2003; Schaller e Crawshaw, 1981).

Em diversas regiões do país é comum a interação capivara-homem conflitando com recursos do ambiente, podendo grupos de capivara invadirem terrenos, comer plantas ornamentais, morrer afogadas em piscinas, ser atacada por cachorros, causar acidentes automobilísticos e entre ciclistas, sujar as ruas com fezes ou transmitir doenças a seres humanos e outros animais (MOREIRA et al., 2001; RODRIGUES, 2012). Trazendo também riscos para a saúde humana e de seus animais domésticos já que juntamente com os equinos e antas, as capivaras são os principais hospedeiros do carrapato estrela (Amblyomma cajennense), vetor da febre maculosa (Rickettsia rickettsii) no Brasil (LABRUNA et al., 2004; PACHECO, et al., 2009).

A capivara possui capacidade de se adaptar a habitats antrópicos e agrícolas principalmente pela disponibilidade de alimentos, viabilizando aumento da população e sendo até mencionada como praga em diversas regiões do país (FELIX, 2012). É uma espécie que compete por alimento com espécies domésticas e silvestres, especialmente durante a estação da seca, quando a disponibilidade da forragem é baixa, podendo inclusive se tornar um problema para plantações de cana-de-açúcar, milho, arroz, sorgo, banana, feijão, soja, mandioca, abóbora e outras culturas em sua busca por alimento (MOREIRA e MACDONALD, 1996).

O manejo de populações problema pode ser necessário em populações que estejam fora do tamanho desejável, isto é, quando aquela população de animais esteja trazendo interações danosas ao homem e/ou ao meio-ambiente onde habita, sendo necessária uma ação temporária ou contínua que visa apenas reestabelecer o estado normal da população 
ou sua erradicação total ao se tratar de espécies invasoras. Caso a espécie esteja estável e adaptada no ambiente, esta possui a tendência de crescer. O Instituto Brasileiro do Meio Ambiente e dos Recursos Naturais Renováveis - IBAMA, age ativamente manejando a espécie, faz a remoção de parte da população, transfere para criadouros domésticos e realiza o controle da população através da caça comercial. Moreira e Piovezan (2005) citam que as medidas adotadas pelo IBAMA são apenas paliativa, pois a remoção de uma parcela da população apenas reduz a competição entre recursos ambientais, disponibilizando mais alimentos aos animais que restaram e consequentemente aumentando a taxa de nascimentos e de crescimento da população a longo prazo.

Existe uma necessidade real em todo o mundo para controlar o crescimento populacional exacerbado de animais cujas populações podem vir a "explodir" como consequência do desequilíbrio ecológico o que pode acrescentar ao declínio do ecossistema, incluindo as capivaras, que são também problema de saúde pública humana e economia da agropecuária. A necessidade de controlar o crescimento destas populações, e de se aproveitar outros benefícios associados a castração de animais, levou a vários métodos de contracepção, incluindo a imunocontracepção que demonstrou potencial como uma forma segura e ética de controlar superpopulações em diversos ecossistemas (KUTZLER \& WOOD, 2006; NAZ et al., 2005; BARBER et al., 2001).

A capivara se apresenta como um animal dócil em relação aos humanos e de fácil manejo, possibilitando que seja estudada a viabilidade da utilização de vacinas contraceptivas, mas deve-se atentar que por ser uma espécie social é necessário um manejo de grupos e não de indivíduos isolados (ANDRADE, et al., 1998). O método de captura mais adequado é o brete ou curral, desde que devidamente autorizado pelo IBAMA (IBAMA, 2000), o brete consiste em um pequeno local cercado construído especialmente para captura e manejo dos indivíduos, em seu interior ou a caminho deste, é fornecido alimento regularmente para atrair os animais, facilitando sua adaptação durante a captura (PEREIRA e ESTON, 2007). 


\section{METODOLOGIA}

Durante o período de setembro a março dos anos de 2019 e 2020, os animais-alvo foram condicionados com petiscos diversos, incluindo frutas, grãos e gramíneas que eram ofertados ao soar de um apito ultrassônico tipicamente utilizado para condicionamento de animais tais como o cão doméstico.

Os alimentos oferecidos foram principalmente cana-de-açúcar associada ao milho, mistura amplamente aceita pelas capivaras locais. Também foi relatada a aceitação de casca de mandioca, folhas de repolho, couve flor, couve e cenoura. Por vezes, Ihes foram oferecidas frutas e hortaliças, como mamão, banana, manga, chuchu e rabanete que foram rejeitadas.

Como métodos de identificação foram utilizados a técnica de mossagem, onde se realizam cortes nas orelhas condizentes com um padrão numeral, e a tricotomia lateral do pêlo, que poderia ser avistada à distância.

O condicionamento foi realizado cinco dias por semana por um grupo de diferentes alunos participantes do programa de iniciação científica nos turnos da manhã e tarde a fim de habituar os animais com a presença e interação humana, e principalmente para atraí-los para os dois bretes fixos existentes nos arredores do lago, onde era possibilitada sua contenção e consequente imunização, atividades estas que foram realizadas durante os dias em que o zoológico se encontrava fechado para visitação visando reduzir o estresse dos animais manejados.

Após a entrada do brete, os animais foram anestesiados com uso de dardos anestésicos atirados através de zarabatanas de modo a atingir a via intramuscular da anca. Ao apresentar um quadro de anestesia geral, foram contidos através de amarras nos membros superiores e inferiores, além disto se utilizou um escudo de madeira sobre o animal de modo que, caso acordasse, não pudesse olhar para trás onde se encontrava a equipe, evitando maior pânico no animal. Assim, foi possível submeter os animais à exames clínicos como ultrassonografia intravaginal, coleta de sangue, e aplicação das vacinas contraceptivas. 


\section{RESULTADOS E DISCUSSÃO}

Manter o interesse das capivaras no condicionamento foi um trabalho difícil; um dos fatores negativos que afetaram o condicionamento através de petiscos foi a época desfavorável do ano, pois, durante o período chuvoso há grande oferta de forragem natural e as capivaras se tornam menos dispostas a sair em busca de mais alimento, principalmente aqueles ofertados por humanos. As atividades de manejo das capivaras realizadas pelos integrantes do projeto avançaram em um rumo desfavorável ao decorrer da frequência crescente de chuvas, já que os animais alvo se tornaram cada vez mais desinteressados no condicionamento embora os laços de confiança entre humanos e animais tenham se solidificado ao longo dos meses. Dessa forma, a melhor estação do ano para o condicionamento é no inverno, quando ocorre a redução na disponibilidade alimentos de forma natural para as capivaras. (PEREIRA e ESTON, 2007).

O horário da oferta do alimento, também teve influência no sucesso do condicionamento. Boa parte do manejo foi realizada durante o turno da manhã, no entanto, apesar de Ojasti (1973) e Felix (2012) descreverem capivaras de vida livre como animais que buscam se alimentar pela manhã esse horário se demonstrou o menos efetivo para o condicionamento, pois ao invés de saírem em busca de alimento o grupo como um todo optou por descansar nas Ilhas dos Macacos e realizar a cecotrofia, ato considerado natural e essencial para estes animais, pois possui alto valor proteico e vitamínico (MENDES, 1999). permanecendo então fora do alcance dos voluntários e demonstrando desinteresse por qualquer outra fonte de alimento. Durante o período da tarde FERRAZ e VERDADE (2001) descrevem que estes animais deveriam se encontrar imersos em água a fim de aliviar o calor e, de fato, muitas das capivaras alvo eram vistas nadando durante este horário. Pequena parcela destas optava por pastar à luz do dia permitindo então que fossem condicionadas e atraídas aos bretes através dos petiscos e apitos. Assim, foi observada maior participação e aceitação das capivaras aos manejos de condicionamento realizados no período da tarde e ao cair da noite, horário em que estão dispostas a forragear. Tais resultados indicam que, em áreas urbanizadas estes animais tendem a converter seus hábitos diurnos por hábitos noturnos de modo a evitar encontros com humanos (OJASTI, 1973; RODRIGUES, 2013)

Os grupos de capivaras dispostos a serem condicionados eram compostos, geralmente, por uma maioria de fêmeas seguidas por um ou dois machos, podendo haver 
também alguns filhotes que se demonstravam curiosos em relação ao manejo além de outros animais que se interessavam pelos alimentos e competiam com as capivaras tais como patos domésticos e macacos-prego. Apesar da aptidão dos machos e filhotes em seguir o rastro de alimento, o interesse do projeto permaneceu inteiramente nas fêmeas solteiras, especialmente jovens, das quais poucas mantinham interesse nos petiscos ao longo do caminho inteiro até chegar ao brete e, por muitas vezes, se assustavam e corriam de volta à água ou apenas preferiam pastejar a grama que se encontrava em abundância devido ao período chuvoso; eventos como a poda de árvores do zoológico também tinham influência direta no desinteresse destes animais nos petiscos oferecidos pois nestas situações preferiam se alimentar das folhas dos galhos recém cortados.

Dentre os animais que foram com sucesso manejados alguns indivíduos em específico se mostraram mais aptos ao condicionamento, respondendo positivamente e sucessivamente aos chamados. Uma fêmea de marcação por tricotomia "C8" que já havia participado de manejos realizados em outros estudos, apelidada como "Augusta" pelos tratadores, acompanhava facilmente os voluntários que reconhecia até o brete e atendia prontamente e sucessivamente aos chamados do apito e de seu nome independentemente de onde estivesse, atraindo consigo outras capivaras. Observou-se a predileção das capivaras como um todo pelo brete localizado ao oeste do lago que, coincidentemente, é uma área onde há maior fluxo de visitantes que por anos interagem com o grupo de capivaras residente naquela região do lago notavelmente tornando-as mais dóceis e suscetíveis ao condicionamento, assim como Augusta (ANDRADE, et al., 1998).

Todas as fêmeas condicionadas com sucesso, contidas e imunizadas tiveram prenhez confirmada através de ultrassonografia intravaginal e se encontravam em estágio final de gestação. Isto é condizente com a literatura que relata maior taxa de nascimentos de acordo com o aumento das chuvas e disponibilidade de alimentos (HERRERA E MOREIRA, 1996; FELIX, 2012). Este achado foi desfavorável a administração da vacina contraceptiva que visava evitar a proliferação do roedor de maneira antecedente à cópula, ainda assim, foram administradas doses aos animais capturados que foram acompanhados até o nascimento de suas ninhadas as quais se apresentaram plenamente saudáveis e dentro dos padrões previstos em situações naturais sem interferência humana. 


\section{CONCLUSÃO}

Ao decorrer das sessões de condicionamento foi relatado a falta de interesse nos animais em acompanhar o rastro de petisco. Diferentes fatores ambientais atuaram na mudança de comportamentos das capivaras durante ao ano, variando sua dieta de acordo com a época de chuvas, horário de manejo, disponibilidade de forragem no ambiente, predileção de aperitivos oferecido e frequência de contato com humanos - que impactou a docilidade dos animais. Durante o período de atividades foi possível concluir que este tipo de manejo com capivaras é mais eficiente durante os períodos de seca, no horário crepuscular e noturno, através da oferta de cana-de-açúcar e milho. Portanto, para animais que habitam ambientes antropizados e, principalmente para estes grupos em específico do Jardim Zoológico de Brasília, se mostra necessária a adaptação do horário de manejo e condicionamento para que seja realizado durante o período crepuscular e noturno. Além disso, houveram dificuldades em diferenciar os indivíduos pois o método de identificação através da técnica de mossagem se mostrou pouco eficiente em animais de vida livre, já que ao longo do tempo a ausência da manutenção dos cortes resulta em certa regeneração, além da existência de cortes resultantes de brigas ou outras interações com o ambiente que podem ser confundidos por aqueles feitos propositalmente, dificultando o contar e acarretando em erros de identificação. Outro método de identificação disponibilizado foi o da tricotomia, este sendo remanescente de outros manejos já realizados com as capivaras trabalhadas, porém, poucos animais ainda apresentavam esta identificação de curto-prazo. Foi considerada a utilização de brincos identificadores, porém, esta opção foi recusada pela administração do zoológico pois poderia causar estranhamento e rejeição por partes dos visitantes, no entanto, é uma metodologia cabível de ser utilizada em outras situações podendo ser aliada ao uso de microchips subcutâneos. 


\section{REFERÊNCIAS BIBLIOGRÁFICAS}

1. ANDRADE, Paulo César Machado; et al. Efeitos do Tamanho da Área, da Dieta e da Idade Inicial de Confinamento sobre Capivaras (Hydrochoerus hydrochaeris hydrochaeris L. 1766) em Crescimento. Revista Brasileira de Zootecnia, v. 27, n. 2, p. 292-299, 1998.

2. BARBER, M. R. et al. Immunolocalization of zona pellucida antigens in the ovarian follicle of dogs, cats, horses and elephants. Theriogenology, v. 55, n. 8, p. 1705-1717, 2001.

3. BARBOSA, Larissa Pires et al. Caracterização da colpocitologia em capivaras (" Hydrochoerus hydrochaeris"). Revista Brasileira de Saúde e Produção Animal, v. 8, n. 4, 2007.

4. FERRAZ, K. P. M. B.; VERDADE, Luciano M. Ecologia comportamental da capivara: bases biológicas para o manejo da espécie. A Produção Animal na Visão dos Brasileiros. Sociedade Brasileira de Zootecnia, Piracicaba, SP, Brasil, p. 589-595, 2001.

5. FERRAZ, K. P. M. B. et al. Biologia e manejo da capivara: do controle de danos ao máximo rendimento sustentável. A produção animal na visão dos brasileiros. Piracicaba, Sociedade Brasileira de Zootecnia, 927 p, p. 580-588, 2001.

6. FELIX, Gisele Aparecida et al. Comportamento alimentar e qualidade de carne de capivara (Hydrochoerus hydrochaeris Linnaeus, 1766) de vida livre, em áreas agrícolas. 2012.

7. IBAMA - Instituto Brasileiro do Meio Ambiente e dos Recursos Naturais Renováveis. 2000. Primeiro Curso de diagnóstico e Manejo de Capivaras no Estado de São Paulo: plano de manejo de capivaras (Hydrochoerus hydrochaeris) de vida livre no Estado de São Paulo. Pirassununga: Ibama-SP

8. KUTZLER, Michelle; WOOD, Anna. Non-surgical methods of contraception and sterilization. Theriogenology, v. 66, n. 3, p. 514-525, 2006.

9. LABRUNA, M. B.; LEITE, R. C.; GOBESSO, A. A. O.; GENARI, S. M.; KASAI, N. Strategic control of the tick Amblyomma cajennense on horses. Ciência Rural, v. 34, n. 1, p.195-200, 2004 
10. MACDONALD, D. W. Dwindling resources and the social behaviour of capybaras,(Hydrochoerus hydrochaeris)(Mammalia). Journal of Zoology, v. 194, n. 3, p. 371-391, 1981.

11. MOREIRA, J. R; PIOVEZAN, U. Conceitos de manejo de fauna, manejo de população problema e o exemplo da capivara. Brasília: Embrapa Recursos Genéticos e Biotecnologia, 2005. 23p.

12. MOREIRA, J. R.; MACDONALD, D. W. Capybara Use and Conservation in South America. In: TAYLOR, V. J.; DUNSTONE, N. (Ed.) The Exploitation of Mammal Populations. London: Chapman \& Hall, 1996. p. 88-101. Capítulo 8

13. MOREIRA, J. R.; PINHA, P. R. S.; CUNHA, H. J. Capivaras do Lago Paranoá. In: FONSECA, F. O. (Ed.) Olhares Sobre o Lago Paranoá. Brasília: Secretaria de Meio Ambiente e Recursos Hídricos, 2001. p.141-147.

14. MENDES, A. Determinação da ocorrência de cecotrofia em capivaras (Hydrochoerus hydrochaeris hydrochaeris L. 1766). 1999. Tese de Doutorado. M. Sc. Dissertation Escola Superior de Agricultura "Luiz de Queiroz", Universidade de São Paulo, Piracicaba.

15. NAZ, Rajesh K. et al. Recent advances in contraceptive vaccine development: a mini-review. Human Reproduction, v. 20, n. 12, p. 3271-3283, 2005.

16. OJASTI, Juhani. Estudio biológico del chigüire o capibara. Caracas: Fondo Nacional de Investigaciones Agropecuarias, 1973.

17. PACHECO, R. C.; HORTA, M. C.; PINTER, A.; MORAES-FILHO, J. MARTINS, T. F.; NARDI, M. S.; SOUZA, S. S. A. L.; SOUZA, C. E.; SZABÓ, M. P. J.; RICHTZENHAIN, L. J.; LABRUNA, M. B. Pesquisa de Rickettsia spp em carrapatos Amblyomma cajennense e Amblyomma dubitatum no Estado de São Paulo. Revista da Sociedade Brasileira de Medicina Tropical, v.42, n.3, p.351- 353, 2009.

18. PEREIRA, Hugo da Fonseca Alves; ESTON, M. R. Biologia e manejo de capivaras (Hydrochoerus hydrochaeris) no parque estadual Alberto Löfgren, São Paulo, Brasil. Revista do Instituto Florestal, v. 19, n. 1, p. 55-64, 2007.

19. RODRIGUES, Marcos Vinícius et al. Comportamento de um grupo de capivaras em uma área urbanizada. Acta Veterinaria Brasilica, v. 7, n. 3, p. 212-217, 2013.

20. SCHALLER, G. S. and P. G. Crawshaw. 1981. Social organization in a capybara population. Saugetierkundliche Mitteilungen 29: 3-16. 